\title{
PENILAIAN TINGKAT KESEHATAN BANK UMUM SYARIAH DEVISA MENGGUNAKAN METODE RISK BASED BANK RATING (RBBR) PERIODE 2014-2016
}

\author{
Eska Prima Monique, Andriani Prawitasari \\ Fakultas Ekonomi Universitas Dehasen Bengkulu \\ monique.ds@unived.ac.id
}

\begin{abstract}
ABSTRAK
Eska Prima Monique, Andriani Prawitasari; Bank menghadapi permasalahan dalam menentukan strategi bisnis dalam pengelolaan usahanya. strategi bisnis ini kemudian akan dijadikan sebagai landasan serta kerangka kerja untuk mewujudkan sasaran kerja yang telah ditentukan oleh manajemen. Dalam sepuluh tahun terakhir, perbankan syariah mengalami pertumbuhan yang pesat, terutama sejak dikeluarkannya undang-undang no. 10 tahun 1998. penelitian ini menggunakan tiga metode penilaian pendekatan risiko (Risk Based Bank Rating) yaitu aspek profil risiko (NPL,LDR), earning rasio (ROA, NIM), dan kecukupan permodalan (CAR). Sedangkan untuk aspek good corporate governance (GCG), tidak dipergunakan karena membutuhkan data primer yang menyangkut kerahasiaan bank. Populasi pengambilan sampel dalam penelitian ini adalah bank umum swasta devisa, cara pengambilan sampel dengan purposive sampling yaitu mengambilan sampel dengan kriteria tertentu. Populasi untuk foreign exchange bank ada sebanyak 35, namun penelitian ini hanya menggunakan 5 bank syariah (berdasarkan kriteria yang telah di tetapkan). Berdasarkan hasil penelitian ini seluruh sampel Perbankan Syariah Devisa menunjukkan hasil kinerja CAR dengan predikat sangat sehat. Kendati tahun 2015 kinerja Non Performing Loan (NPL) sempat mengalami penurunan, namun pada tahun 2016 seluruh Perbankan Syariah Devisa mampu melakukan perbaikan kinerja NPL menjadi dibawah 5\% (predikat kinerja sehat). Tahun 2014-2016 sebanyak 4 dari 5 Perbankan Syariah Devisa menunjukkan kinerja Loan To Deposit Ratio (LDR) dengan predikat cukup sehat (LDR diantara 85\% dan 100\%). Kinerja Net Interest Margin (NIM) seluruh sampel Perbankan Syariah Devisa tahun 2014-2016 cenderung sangat sehat (NIM >3\%). Sehingga dapat dikatakan bahwa perusahaan mampu memperoleh keuntungan dari pendapatan bunga. Selama tahun 2014-2016 kinerja Return on Asset (ROA) sampel Perbankan Syariah Devisa juga cenderung mengalami peningkatan, jika dalam 2 tahun sebelumnya (2014 dan 2015) hanya 2 dari 5 bank sampel yang memiliki ROA diatas 1,25\% maka pada tahun 2016 ada 3 dari 5 bank sampel yang mampu meraih kinerja ROA bahkan diatas 1,5\% (predikat sangat sehat).
\end{abstract}

\section{ABSTRACT}

Eska Prima Monique, Andriani Prawitasari; Banks face problems in determining business strategy in managing their business. this business strategy will then be used as the foundation and framework to realize the work goals that have been determined by management. In the past ten years, sharia banking has grown rapidly, especially since the issuance of statute no. 10 of 1998. This research uses three risk assessment method (Risk Based Bank Rating), which are risk profile aspect (NPL, LDR), earning ratio (ROA, NIM), and capital adequacy (CAR). As for the aspects of good corporate governance (GCG), it is not used because it requires primary data concerning bank secrecy. The sample population in this study is sharia foreign exchange bank. while the sampling method used purposive sampling (i.e. taking samples with certain criteria). The population for foreign exchange banks is 35, but this study only uses 5 sharia banks (based on predetermined criteria). Based on the results of this study the entire sample of Sharia Banking Foreign Exchange shows the results of CAR performance with a very healthy predicate. Although in 2015 the performance of Non Performing Loan (NPL) had decreased, but in 2016 all Sharia Foreign Exchange Banks were able to improve NPL performance to below 5\% (healthy performance predicate). In 2014-2016, there are 4 out of 5 Sharia Foreign Currency Bankers performing Loan To Deposit Ratio (LDR) with a fairly healthy predicate (LDR is between $85 \%$ and 100\%). Net Interest Margin (NIM) performance of all samples of Foreign Exchange Sharia Banking in 2014-2016 tends to be very healthy (NIM> 3\%). So it can be said that the company is able to profit from interest income. During 2014-2016 the Return on Asset (ROA) performance of the Sharia Banking Foreign Exchange (ROA) sample also tended to increase, if in the previous two years (2014 and 2015) only 2 out of 5 sample banks have ROA above 1.25\% then in 2016 there 3 out of 5 sample banks are able to achieve ROA performance even above 1.5\% (very healthy predicate)

Key Words: sharia foreign exchange bank, risk based bank rating (RBBR), NPL, LDR ROA, NIM, CAR 


\section{LATAR BELAKANG}

Pesatnya pertumbuhan bisnis perbankan saat ini ditandai dengan banyak munculnya perbankan baru yang ada di Indonesia. Ketatnya persaingan ini membuat setiap perbankan menyusun strategi bagaimana dapat bertahan dan memperbaiki manajemen perbankan. Menurut Ali (2004) kunci sukses dalam persaingan pasar global adalah kualitas total yang mencakup pada kualitas produk, kualitas biaya atau harga, kualitas pelayanan, kualitas penyerahan tepat waktu dan kepuasan-kepuasan lain yang terus berkembang guna memberikan pelayanan terbaik kepada nasabah. Bank dihadapkan pada penentuan strategi dalam pengelolaan usahanya. Penentuan strategi akan dijadikan sebagai landasan dan kerangka kerja untuk mewujudkan sasaran-sasaran kerja yang telah ditentukan oleh manajemen.

Dalam sepuluh tahun terakhir perbankan syariah mengalami pertumbuhan dan perkembangan yang pesat, terutama sejak dikeluarkannya undang-undang no. 10 tahun 1998. Ketentuan Bank Indonesia ini memberi izin untuk pembukaan bank syariah yang baru maupun pendirian Unit Usaha Syariah (UUS) (Andini, 2015)

Tujuan perbankan syariah sama dengan perbankan kovesional yaitu agar dapat mengelola dana, menghasilkan keuntungan dengan cara pemberian kredit, penyimpanan dana, pembiayaan kegiatan usaha, dan hal lainnya. Pada penelitian ini menggunakan perbankan swasta umum nasional devisa yang terdiri atas tiga puluh lima perbankan, namun peneliti lebih menfokuskan pada perbankan syariah saja sehingga diperolahlah lima perbankan syariah yang terdaftar dalam bursa efek Indonesia.

Dalam pergerakan perekonomian suatu negara, bank merupakan lembaga khusus yang mempunyai peran strategis. Bank merupakan suatu lembaga keuangan yang mempermudah masyarakat dalam menyimpan dana, membutuhkan dana dan kegiatan usahanya bergerak di bidang keuangan (Yacheva,2016). Menurut undang-undang no 10 tahun 1998 bank merupakan lembaga perantara keuangan (financial intermediary) yang mengumpulkan dana dari masyarakat dan menyalurkannya kembali kepada masyarakat dengan berupa kredit. Bank hendaknya harus menjaga kepercayaan yang di berikan masyarakat dalam mengelola dana mereka. Hal itu dapat terwujud dengan cara bank menjaga kesehatan kinerjanya, karena kinerja sangat penting bagi suatu lembaga. Menurut Susilo (2002) dengan mengetahui tingkat kesehatan bank, stakeholder dapat dengan mudah menilai kinerja lembaga perbankan tersebut. Oleh karena itu agar dapat berjalan dengan lancar, kinerja bank harus dalam keadaan baik.

Perbankan memiliki tiga kegiatan utama, diantaranya menghimpun dana dari masyarakat dalam bentuk simpanan, menyalurkan dana kepada masyarakat dalam bentuk kredit, dan bentuk-bentuk lainnya dalam rangka meningkatkan taraf hidup masyarakat banyak. Bank sebagai perantara antara pihak yang memiliki kelebihan dana dengan pihak yang memerlukan dana. Menurut Peraturan Bank Indonesia No. 13/1/PBI/2011, "Kesehatan bank merupakan cerminan kondisi dan kinerja bank sebagai sarana bagi otoritas pengawas dalam menetapkan strategi dan fokus pengawasan terhadap bank". Perbankan merupakan lembaga yang di berikan kepercayaan oleh masyarakat untuk mengelola dana mereka, namun para pemilik dan atersebut dapat dengan sewaktu-waktu menarik dana yang dimilikinya dan bank harus dapat mengembalikan dana tersebut jika ingin tetap mendapat kepercayaan. Penarikan dana secara bersamaan tersebut dapat menimbulkan permasalahan likuiditas bagi bank dan selanjutnya dapat menimbulkan kebangkrutan bank (Simorangkir, 2004).

Mengingat akan pentingnya tingkat kesehatan suatu bank, maka perlu penilaian tingkat kesehatan bank. Penilaian ini bertujuan guna menentukan apakah bank dalam kondisi yang sangat sehat, sehat, cukup sehat, kurang sehat, atau bahkan tidak sehat sehingga bank tersebut harus tetap dijalankan atau bahkan dapat diberhentikan kegiatan operasinya. Metode penilaian kesehatan bank dari selalu berubah menyesuaikan perkembangan saat ini. Penyempurnaan penilaian kesehatan bank perlu dilakukan agar dapat mencerminkan kondisi kesehatan bank saat ini maupun di waktu yang akan datang (Taswan, 2006)

Menurut Peraturan Bank Indonesia No. 13/1/PBI/2011 penilaian tingkat kesehatan bank menggunakan pendekatan berdasarkan risiko atau RBBR (Risk-Based Bank Rating) yang merupakan penilaian komprehensif dan terstruktur terhadap hasil kinerja dan profil risiko.Penilaian ini meliputi empat faktor penilaian yaitu risk profile (profil risiko), good corporate governance (GCG), earning (rentabilitas), dan capital (permodalan).

Penilaian risk profile (profil risiko) dianalisis menggunakan rasio NPL (non perfoming loan) dan rasio LDR (loan to deposit ratio). Penilaian good corporate governance (GCG) tidak dapat dilakukan analisis karena menyangkut kerahasian bank dan penilaian ini menggunakan metode kualitatif.Pengukuran earning (rentabilitas) menggunakan dua rasio yaitu rasio return on assets (ROA) dan rasio net interest margin (NIM). Sedangkan penilaian capital (permodalan) menggunakan capital adequency ratio (CAR). Berdasarkan latar belakang masalah yang dipaparkan, maka peneliti tertarik 
mengajukan penelitian dengan judul "Penilaian Tingkat Kesehatan Bank Umum Syariah Devisa Dengan Menggunakan Metode Risk Based Bank Rating (RBBR) Periode 2014-2016"

\section{Landasan Teori \\ Bank}

Menurut Taswan (2010) bank merupakan sebuah lembaga atau perusahaan yang menghimpun dana dari pihak yang kelebihan dana (surplus spending unit) kepada pihak yang kekurangan dana (deficit spending unit). Dana tersebut dapat berupa berupa giro, deposito tabungan dan simpanan yang lain,, pemberian dana tersebut diharapkan dapat meningkatkan kesejahteraan masyarakat. Sedangkan menurut Kasmir (2012) perbankan adalah lembaga keuangan yang melakukan menghimpun dana dari masyarakat, kemudian dana tersebut di salurkan kembali kepada masyarakat dan lembaga lain nya.

\section{Laporan Keuangan}

Menurut Ikatan Akuntan Indonesia laporan keuangan merupan suatu proses pengimpunan datadata yang kemudian diproses kedalam bentuk neraca,laporan laba rugi, maupun catatan-catatan yang lain (IAI, 2009). Menurut Kasmir (2012) laporan keuangan bank adalah laporan yang menunjukan kondisi keuangan bank secara keseluruhan. Dari laporan ini dapat diketahui bagaimana kondisi bank yang sesungguhnya, termasuk kekurangan dan keunggulan yang dimiliki.

Baridwan (1992) mengemukakan bahwa laporan keuangan merupakan ringkasan dari suatu proses pencatatan transaksi-transaksi keuangan yang terjadi selama dua tahun buku yang bersangkutan. Sedangkan menurut Sundjaja dan Barlian (2001) laporan keuangan adalah suatu laporan yang menggambarkan hasil dari proses akuntansi yang digunakan sebagai alat komunikasi untuk pihak-pihak yang berkepentingan dengan data keuangan atau aktivitas perusahaan.

Jadi laporan keuangan bersifat historis serta menyeluruh dan sebagai suatu progress report. Laporan keuangan terdiri dari data-data yang merupakan hasil dari kombinasi antara fakta yang telah dicatat, prinsip-prinsip dan kebiasaan-kebiasaan dalam akutansi serta pendapat pribadi.

\section{Kesehatan bank}

Untuk menilai kinerja perbankan sanggat erat kaitan nya degan penilaian kesehatan yang di lakukan oleh bank indonesia pada bank yang ada di Indonesia. Menurut peraturan Bank Indonesia No. 5/10/PBI/ tahun 2004 untuk menilai kesehatan bank di Indonesia menggunakan metode CAMEL yang terdiri atas aspek Capital, Asset, Management, Earning dan Liquidity. Namun pada tahun 2011 di lakukan perubahan peraturan untuk menggantikan CAMEL. Melalui Peraturan Bank Indonesia Nomor 13/1/PBI/2011 bank wajib melakukan penilaian tingkat kesehatan bank dengan menggunakan pendekatan risiko (Risk Based Bank Rating) yang meliputi aspek profil risiko (risk profile), good corporate governance (GCG), rentabilitas (earnings) dan permodalan (capital)

\section{Metode Risk Based Bank Rating (RBBR)}

Dalam penelitian ini menggunakan tiga metode penilaian pendekatan risiko (Risk Based Bank Rating) yaitu aspek profil risiko (risk profile), rentabilitas (earnings) dan permodalan (capital).Sedangkan untuk aspek good corporate governance (GCG), tidak dipergunakan karena membutuhkan data primer yang menyangkut kerahasiaan bank. Berikut penjelasan mengenai tiga faktor penilaian:

\section{Profil Risiko (Risk Profile)}

Pada profil risiko ini diukur dengan menggunakan rasio Non Performing Loan (NPL) dan Loan To Deposit Ratio (LDR)

Rasio Non Performing Loan (NPL) diukur dengan menggunakan rumus:

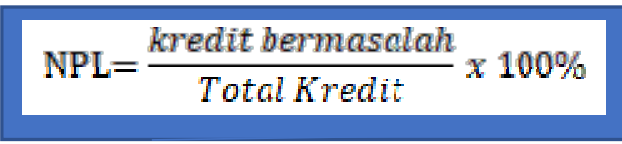

Sumber: Jumingan (2011) 
Tabel 1. Predikat Kesehatan berdasarkan NPL

\begin{tabular}{rcc}
\hline No & Rasio NPL & Predikat \\
\hline $\mathbf{1}$ & $0 \%<\mathrm{NPL}<2 \%$ & Sangat Sehat \\
$\mathbf{2}$ & $2 \% \leq \mathrm{NPL} \leq 5 \%$ & Sehat \\
$\mathbf{3}$ & $5 \% \leq \mathrm{NPL} \leq 8 \%$ & Cukup Sehat \\
$\mathbf{4}$ & $8 \% \leq \mathrm{NPL} \leq 11 \%$ & Kurang Sehat \\
$\mathbf{5}$ & $\mathrm{NPL}>11 \%$ & Tidak Sehat \\
\hline
\end{tabular}

Sumber : SE BI 6/23/DPNP

Rasio Loan To Deposit Ratio (LDR) di ukur dengan menggunakan rumus:

$$
\mathrm{LDR}=\frac{\text { kredit }}{\text { dana pihak ketiga }} \times 100 \%
$$

Sumber: Irmayanto, dkk (2009)

Tabel 2. Predikat Kesehatan berdasarkan LDR

\begin{tabular}{rcc}
\hline No & Rasio LDR & Predikat \\
\hline $\mathbf{1}$ & $50 \%<\mathrm{LDR} \leq 75 \%$ & Sangat Sehat \\
$\mathbf{2}$ & $75 \%<\mathrm{LDR} \leq 85 \%$ & Sehat \\
$\mathbf{3}$ & $85 \%<\mathrm{LDR} \leq 100 \%$ & Cukup Sehat \\
$\mathbf{4}$ & $100 \%<\mathrm{LDR} \leq 120 \%$ & Kurang Sehat \\
$\mathbf{5}$ & $\mathrm{LDR}>120 \%$ & Tidak Sehat \\
\hline
\end{tabular}

Sumber : SE BI 6/23/DPNP

\section{Rentabilitas (earnings)}

Pada penilaian ini pengukuran dengan menggunakan dua rasio yaitu:

ROA (Return On Asset)

$$
\mathrm{ROA}=\frac{\text { laba sebelum pajak }}{\text { rata }- \text { rata total aset }} \times 100 \%
$$

Sumber: Taswan (2006)

\section{Tabel 3. Predikat Kesehatan berdasarkan ROA}

\begin{tabular}{ccc}
\hline No & Rasio ROA & Predikat \\
\hline $\mathbf{1}$ & $\mathrm{ROA}>1,5 \%$ & Sangat Sehat \\
$\mathbf{2}$ & $1,25 \%<\mathrm{ROA} \leq 1,5 \%$ & Sehat \\
$\mathbf{3}$ & $0,5 \%<\mathrm{ROA} \leq 1,25 \%$ & Cukup Sehat \\
$\mathbf{4}$ & $0 \%<\mathrm{ROA} \leq 0,5 \%$ & Kurang Sehat \\
$\mathbf{5}$ & $\mathrm{ROA} \leq 0 \%$ & Tidak Sehat \\
\hline
\end{tabular}

Sumber :www.bi.go.id

NIM (Net Interest Margin)

$$
\mathrm{NIM}=\frac{\text { Pendapatan bunga bersih }}{\text { rata }- \text { rata aktiva produktif }} \times 100 \%
$$

Sumber: Taswan (2006) 
Tabel 4. Predikat Kesehatan berdasarkan NIM

\begin{tabular}{ccc}
\hline No & Rasio NIM & Predikat \\
\hline $\mathbf{1}$ & $\mathrm{NIM}>3 \%$ & Sangat Sehat \\
$\mathbf{2}$ & $2 \%<\mathrm{NIM} \leq 3 \%$ & Sehat \\
$\mathbf{3}$ & $1,5 \%<\mathrm{NIM} \leq 2 \%$ & Cukup Sehat \\
$\mathbf{4}$ & $1 \%<\mathrm{NIM} \leq 1,5 \%$ & Kurang Sehat \\
$\mathbf{5}$ & $\mathrm{NIM} \leq 1 \%$ & Tidak Sehat \\
\hline
\end{tabular}

Sumber :www.bi.go.id

\section{Permodalan (capital)}

Rasio ini di ukur dengan menggunakan Capital Adequency Ratio (CAR) dengan rumus sebagai berikut:

$$
\mathrm{CAR}=\frac{\text { Modal }}{\text { aktiva tertimbang memurut resiko }} \times 100 \%
$$

Sumber : Taswan (2006)

Tabel 5. Predikat Kesehatan berdasarkan CAR

\begin{tabular}{ccc}
\hline No & Rasio CAR & Predikat \\
\hline $\mathbf{1}$ & CAR $>12 \%$ & Sangat Sehat \\
$\mathbf{2}$ & $9 \%<\mathrm{CAR} \leq 12 \%$ & Sehat \\
$\mathbf{3}$ & $8 \%<\mathrm{CAR} \leq 9 \%$ & Cukup Sehat \\
$\mathbf{4}$ & $6 \%<\mathrm{CAR} \leq 8 \%$ & Kurang Sehat \\
$\mathbf{5}$ & $\mathrm{CAR} \leq 6 \%$ & Tidak Sehat \\
\hline
\end{tabular}

Sumber :www.bi.go.id

\section{Kerangka Analisis}

Untuk mempermudah alur pemikiran maka dibuat kerangka analisis sebagai gambaran penelitian. Kerangka analisis penelitian ini adalah

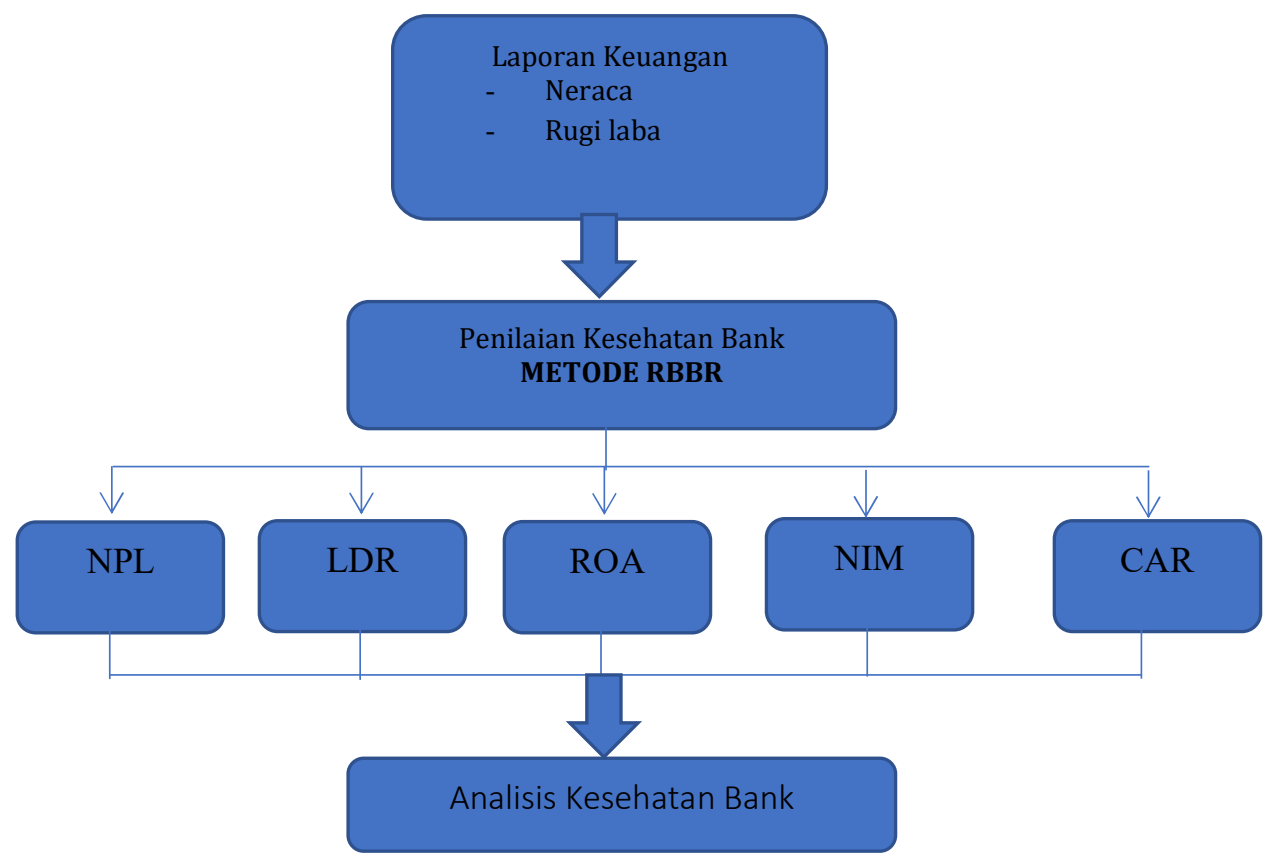

Gambar 1. Metode Jalur Analisis Penelitian 


\section{Metode Penelitian}

Penelitian ini merupakan penelitian diskriptif dengan pendekatan kuantitatif. Data yang di kumpulkan adalah laporan keuangan bank syariah devisa tahun 2014-2016. Peneliti membandingkan rasio keuangan yang merupakan ukuran kinerja keuangan pada perbankan syariah devisa. Rasio-rasio yang diukur menggunakan pendekatan risiko (Risk Based Bank Rating) yaitu aspek profil risiko (risk profile), rentabilitas (earnings) dan permodalan (capital). Yang mana aspek profil risiko(risk profile) menggunakan rasio Non Performing Loan (NPL) dan Loan To Deposit Ratio (LDR). Aspek rentabilitas (earnings) diukur dengan menggunakan rasio ROA (Return On Asset) dan NIM (Net Interest Margin). Aspek permodalan (capital) diukur dengan Capital Adequency Ratio (CAR).

Populasi pengambilan sampel dalam penelitian ini adalah bank umum swasta devisa, cara pengambilan sampel dengan purposive sampling yaitu mengambilan sampel dengan kriteria tertentu. Populasi bank umum swasta nasional devisa ada 35 bank, namun penulis hanya menggunakan 5 bank syariah yang terdapat didalam populasi sesuai dengan kriteria yang telah di tetapkan.

\begin{tabular}{ccl}
\multicolumn{2}{c}{ Tabel 6 Sampel Penelitian Bank Syariah Devisa tahun 2014-2016 } \\
\hline NO & Kode & Nama Bank \\
\hline $\mathbf{1}$ & BMUI & Bank Muamalat Indonesia \\
$\mathbf{2}$ & BSM & Bank Syariah Mandiri \\
$\mathbf{3}$ & MSIB & Bank Syariah Mega Indonesia \\
$\mathbf{4}$ & PDSB & Bank Panin Dubai Syariah \\
$\mathbf{5}$ & BNIS & Banik BNI Syariah \\
\hline
\end{tabular}

Sumber:data diolah (2018)

\section{Hasil Penelitian Dan Pembahasan}

\section{a. Profil Resiko (Risk Profile)}

\section{Rasio Non Performing Loan (NPL)}

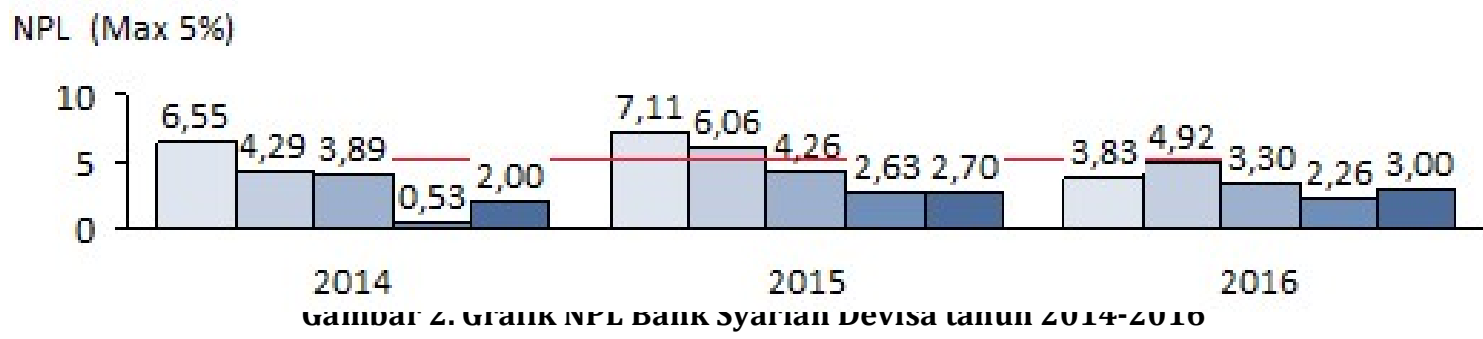

Sumber : data diolah 2018

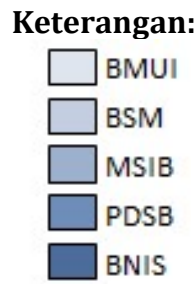

Dari grafik di atas secara umum diketahui bahwa selama 3 tahun periode penelitian telah terjadi peningkatan kinerja Non Performing Loan pada seluruh bank syariah sampel (NPL tahun 2016 dibawah $5 \%$, predikat sehat).

Pada tahun 2014, empat (4) dari lima (5) bank syariah yang sampel menunjukkan nilai rasio Non Performing Loan (NPL) dibawah 5\% dengan predikat sehat (Bank Syariah Mandiri dan Bank Syariah Mega Indonesia dengan nilai 4,29\% dan 3,89\%) dan sangat sehat (Bank Panin Dubai Syariah dan Bank BNI 
Syariah dengan nilai 0,53\% dan 2\%). Sedangkan untuk Bank Muamalat Indonesia hanya memperoleh predikat cukup sehat (NPL 6,55\%).

Sedangkan tahun 2015 kinerja NPL cenderung memburuk karena terjadi peningkatan kredit bermasalah di seluruh bank syariah sampel. Hanya 3 bank syariah sampel yang menunjukkan kinerja NPL dibawah 5\% dengan predikat sehat (yakni Bank Syariah Mega Indonesia 4,26\%, Bank Panin Dubai Syariah 2,63\% dan Bank BNI Syariah 2,70\%). Kendati demikian, dua bank lainnya yaitu Bank Muamalat Indonesia dan Bank Syariah Mandiri masih memperoleh predikat cukup sehat dengan nilai 7,11\% dan $6,06 \%$.

Pada tahun 2016 kinerja Non Performing Loan (NPL) pada seluruh bank syariah sampel berada dibawah 5\% (predikat sehat). Sehingga secara umum diketahui bahwa selama 3 tahun periode penelitian telah terjadi peningkatan kinerja Non Performing Loan pada seluruh bank syariah sampel. Namun perlu menjadi catatan kinerja Non Performing Loan (NPL) untuk Bank BNI syariah semakin menurun dengan trend kenaikan dari 2\% menjadi 3\% meskipun kenaikan tersebut masih dalam rentang predikat sehat.

\section{Rasio Loan To Deposit Ratio (LDR)}

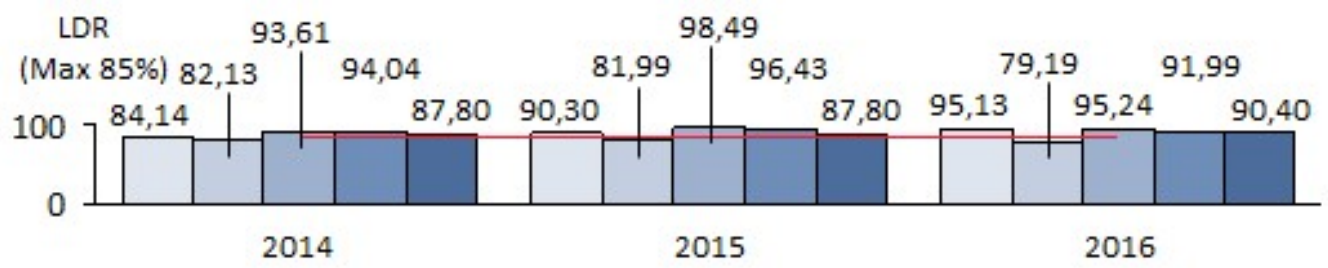

Gambar 3. Grafik LDR Bank Syariah Devisa tahun 2014-2016

Sumber : data diolah 2018

Keterangan

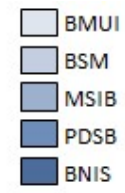

Dari grafik diatas secara umum rata-rata kinerja Loan To Deposit Ratio (LDR) masih cukup sehat. Tahun 2014-2016 keempat bank yaitu Bank Muamalat Indonesia, Bank Syariah Mega Indonesia, Bank Panin Dubai Syariah dan Bank BNI Syariah menunjukkan kinerja LDR dengan predikat cukup sehat (LDR diantara 85\% dan 100\%). Adapun Bank Syariah Mandiri (BSM) memiliki memiliki kinerja Loan To Deposit Ratio (LDR) yang paling baik karena dapat mempertahankan predikat sehat (LDR <85\%), dan selama tahun 2014-2016 BSM mampu menurunkan dari 82,13\% menjadi 79,19\%. Sedangkan Bank Muamalat Indonesia dan Bank BNI Syariah justru sebaliknya, menunjukkan kinerja Loan To Deposit Ratio (LDR) yang cenderung semakin mengalami kenaikan nilai (semakin menjauh dari batasan sehat).

\section{b. Rentabilitas (earnings)}

\section{Rasio ROA (Return On Asset)}

ROA (Min 1,25\%)

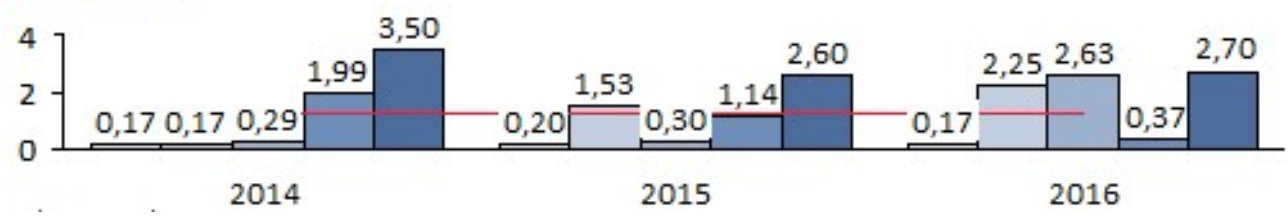

Gambar 4. Grafik ROA Bank Syariah Devisa tahun 2014-2016

Sumber : data diolah 2018

Keterangan

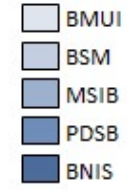


Rasio ini digunakan untuk melihat kemampuan perusahaan dalam mengelola setiap nilai asset yang dimilikinya untuk dapat menghasilkan laba bersih setelah pajak. Berdasarkan grafik Rasio ROA (Return On Asset) ini dapat dikatakan bahwa pada tahun 2014 terdapat tiga perbankan yang masih masuk dalam predikat tidak sehat yaitu Bank Muamalat Indonesia, Bank Syariah Mandiri dan Bank Mega Syariah Indonesia dengan kinerja 0,17\%, 0,17\%, 0,29\%, artinya bahwa kemampuan ketiga bank tersebut untuk dapat menghasilkan laba bersih setelah pajak masih sangat rendah.

Selama tahun 2014-2016 kinerja ROA bank Syariah sampel cenderung mengalami peningkatan jika dalam 2 tahun sebelumnya (2014 dan 2015) hanya 2 dari 5 bank sampel yang memiliki ROA diatas 1,25\% maka pada tahun 2016 ada 3 bank yang bahkan mampu meraih kinerja ROA diatas 1,5\% (predikat sangat sehat). Adapun Bank BNI Syariah menunjukkan kinerja ROA yang paling baik dengan predikat sangat sehat selama periode tahun 2014-2016. Namun perlu diperhatikan bahwa Bank Muamalat Indonesia tetap masih belum beranjak dari kinerja kurang sehat (ROA <0,5\%) sedangkan Bank Panin Dubai Syariah justru cenderung terus terpuruk (ROA merosot dari 1,99\% menjadi 0,37\%).

\section{Rasio NIM (Net Interest Margin)}

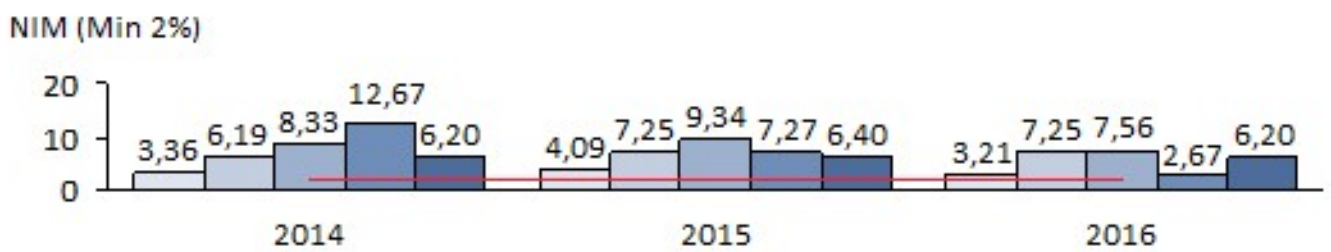

Gambar 5. Grafik NIM Bank Syariah Devisa tahun 2014-2016

Sumber : data diolah 2018

Keterangan

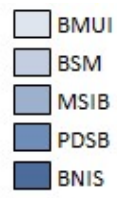

Rasio Net Interest Margin (NIM) menggambarkan selisih tingkat bunga yang harus dibayarkan bank terhadap bunga pinjaman. Berdasarkan grafik Rasio NIM diketahui bahwa kinerja seluruh bank syariah sampel pada tahun 2014-2016 cenderung sangat sehat (NIM >3\%). Sehingga dapat dikatakan bahwa perusahaan mampu memperoleh keuntungan dari pendapatan bunga.

c. Permodalan (Capital)

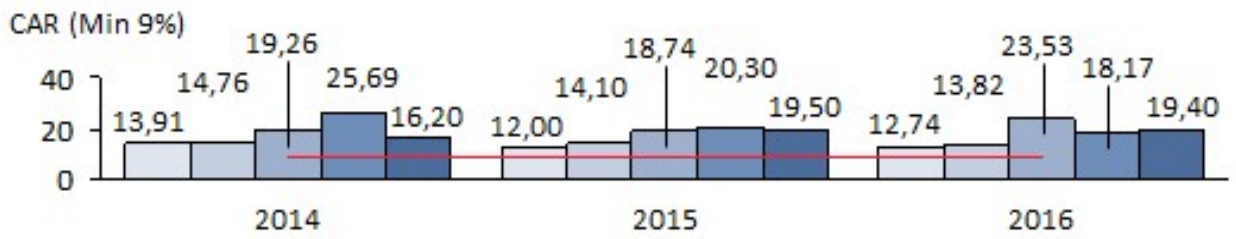

Gambar 6. Grafik CAR Bank Syariah Devisa tahun 2014-2016

Sumber : data diolah 2018

Keterangan

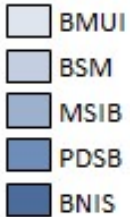

Rasio Capital Adequency kuı (инк) memperlihatkan seberapa besar jumlah seluruh aktiva bank yang mengandung risiko (kredit, penyertaan, surat berharga, tagihan pada bank lain) ikut dibiayai dari modal sendiri disamping memperoleh dana-dana dari sumber-sumber di luar bank (Dendawijaya, 2003). Berdasarkan grafik di atas dapat dilihat dari tahun 2014-2016 kelima bank memiliki predikat sangat 
sehat terutama untuk bank Mega Syariah Indonesia (MSIB) selama tiga tahun terakhir terus memperlihatkan kenaikan yang signifikan dari 19,26\% menjadi 23,53\%.

\section{Analisis Komposit Bank}

\section{a. Bank Muamalat Indonesia (BMUI)}

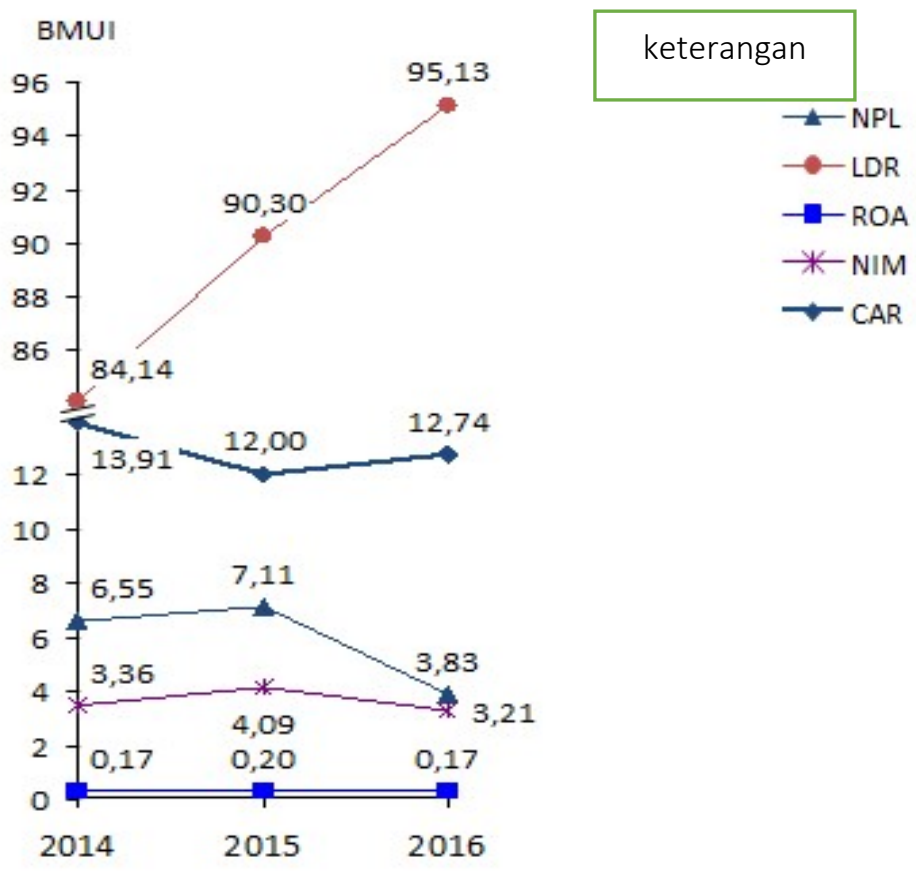

\section{Gambar 7. Grafik Gabungan rasio RBBR Bank Muamalat Indonesia}

Dari grafik diatas dapat dijelaskan bahwa tahun 2014 BMUI memiliki posisi CAR masih sangat sehat, Net Interest Margin (NIM) juga sangat sehat serta nilai Non Performing Loan (NPL) cukup sehat. Sehingga tahun 2015 perusahaan melakukan strategi ekspansi kredit (LDR naik dari 84,14\% menjadi 90,30\%) didukung dengan nilai Net Interest Margin (NIM) yang lebih baik dalam rangka meningkatkan kinerja ROA (dari 0,17\% menjadi 0,20\%). Namun hal ini berdampak pada peningkatan kredit bermasalah (NPL naik dari 6,55\% menjadi 7,11\%) serta penurunan CAR cukup signifikan (dari 13,91\% menjadi $12 \%)$.

Pada tahun 2016 BMUI berupaya menurunkan Net Interest Margin (NIM dari 4,09\% menjadi 3,21\%) dengan harapan dapat meningkatkan kinerja Capital Adequency Ratio (CAR dari 12\% menjadi 12,74\%) guna mendukung strategi ekspansi kredit, hal tersebut dapat dilihat dengan naiknya nilai Loan To Deposit Ratio (LDR) menjadi 95,13\%. Perusahaan melakukan ekspansi secara lebih selektif, hal ini dilihat dari penurunan NPL dari 7,11\% ke 3,83\%. Sayangnya, upaya yang dilakukan selama 3 tahun terakhir ini masih belum mampu mendongkrak kinerja Return On Asset (ROA dengan predikat masih kurang sehat). 


\section{b. Bank Syariah Mandiri (BSM)}

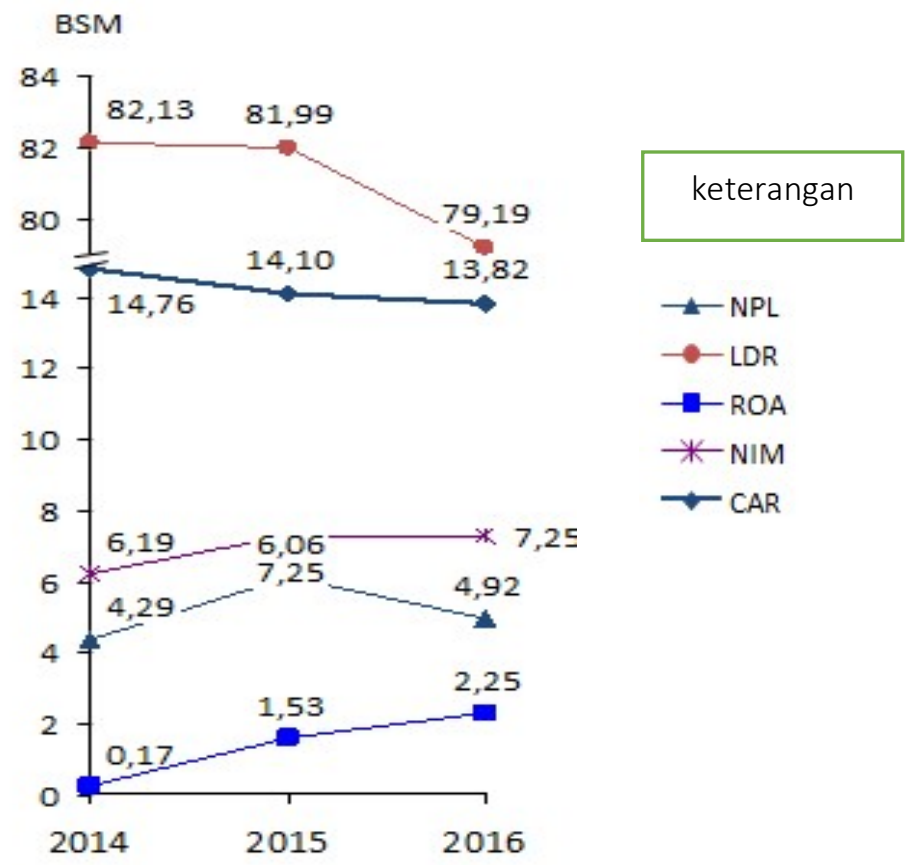

Gambar 8. Grafik Gabungan rasio RBBR Bank Syariah Mandiri (BSM)

Dari grafik diatas dapat diketahui bahwa Bank Syariah Mandiri memiliki kinerja Return On Asset (ROA) yang terus mengalami kenaikan selama tiga tahun terakhir dari 0,17\% menjadi 2,25\% (sangat sehat), didukung oleh perbaikan kinerja Net Interest Margin (NIM dari 6,19\% menjadi 7,25\%). Terlihat pula perbaikan kinerja Loan To Deposit Ratio (LDR turun dari 82,13\% menjadi 79,19\%) dalam 3 tahun terakhir (predikat sehat). Penurunan Capital Adequency Ratio (CAR dari 14,76\% ke 13,82\%) disaat LDR juga terus menurun, dapat diartikan BSM sedang menerapkan strategi pengetatan kredit dalam rangka memperbaiki kinerja Non Perfoming Laon (NPL yang pada tahun sebelumnya mengalami kenaikan dari 4.29\% menjadi 7,25\%, sehingga pada tahun 2016 dapat ditekan menjadi dibawah 5\%).

\section{c. Bank Mega Syariah Indonesia}

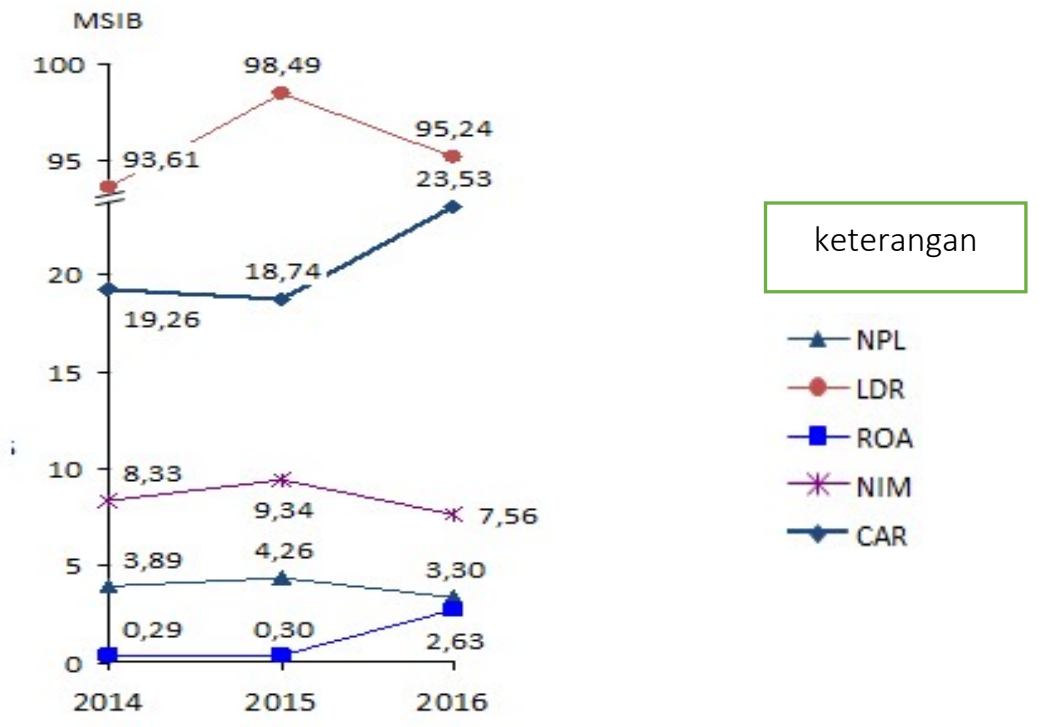

Gambar 9. Grafik Gabungan rasio RBBR Bank Mega Syariah Indonesia (MSIB) 
Dari grafik diatas dapat diketahui bahwa kinerja Net Interest Margin (NIM) Bank Mega Syariah Indonesia pada tahun 2015 mengalami kenaikan dari 8,33\% menjadi 9,34\% hal ini mungkin dapat terjadi ketika bank mulai mendapat banyak keuntungan dari selisih bunga kredit (LDR meningkat dari 93,61\% menjadi $98,49 \%$ ). Namun dengan meningkatnya pemberian kredit, terdapat peningkatan pada kredit bermasalah (NPL dari 3,89\% menjadi 4,26\%) serta penurunan kinerja

Capital Adequency Ratio (CAR) menurun dari 19,26\% menjadi 18,74\%. Adapun strategi MSIB pada tahun 2016 bank adalah dengan menurunkan keuntungan dari selisih bunga kredit (NIM) menjadi 7,56\% dalam rangka memperbaiki kinerja CAR menjadi 23,53\% (predikat sangat sehat), selektif dalam pemberian kredit (memperbaiki kinerja LDR sehingga turun ke 95,24\%) untuk menekan kredit bermasalah NPL turun ke 3,3\% sehingga mampu mendongkrak kinerja ROA dari 0,3\% (kurang sehat) naik menjadi 2,63\% (sangat sehat).

\section{d. Bank Panin Dubai Syariah}

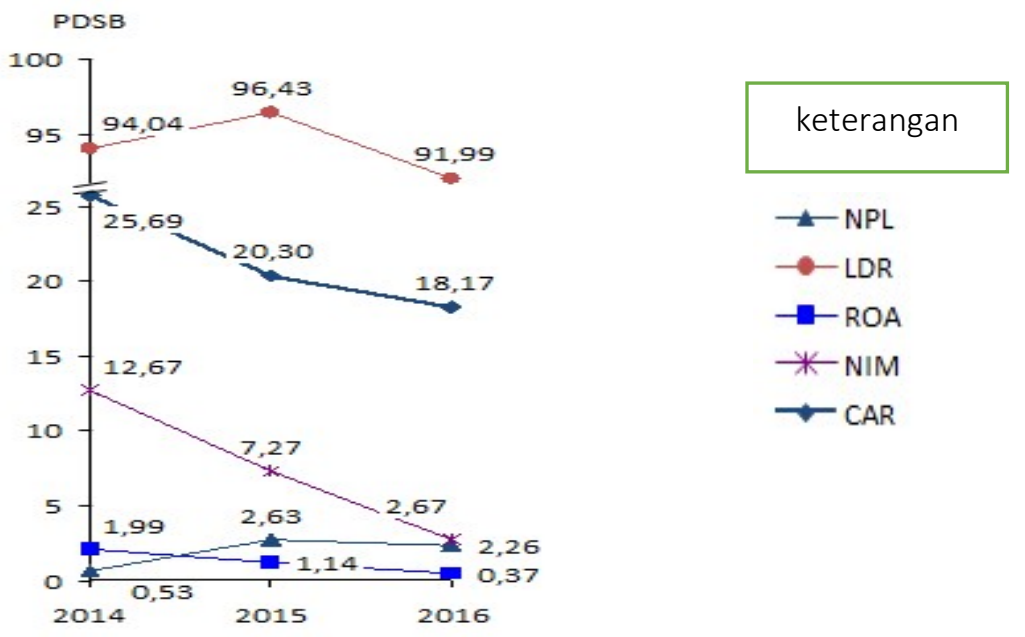

Gambar 9 Grafik Gabungan rasio RBBR Panin Dubai Syariah Bank (PDSB)

Sumber: Data diolah peneliti 2018

Dari grafik diatas nilai Capital Adequency Ratio (CAR) dalam 3 tahun terakhir memiliki nilai yang terus menurun yaitu dari 25,69\% sampai 18,17\%. Sedangkan kinerja Loan To Deposit Ratio (LDR) mengalami perbaikan dengan penurunan nilai dari $94.04 \%$ menjadi $91.99 \%$, penurunan ini mungkin diakibatkan dari bunga yang ditawarkan sebagai bank baru masih tidak menarik (NIM sangat tinggi). PDSB mencoba melakukan penyesuaian pada Net Interest Margin (NIM dari 12,67\% ke 2,67\% masih predikat sehat) namun belum berhasil meningkatkan kinerja CAR (walau masih predikat sangat sehat), hal ini justru berdampak pada terus merosotnya kinerja Return On Asset (ROA 1,99\% ke 0,37\% kurang sehat).

\section{e. Bank BNI Syariah}

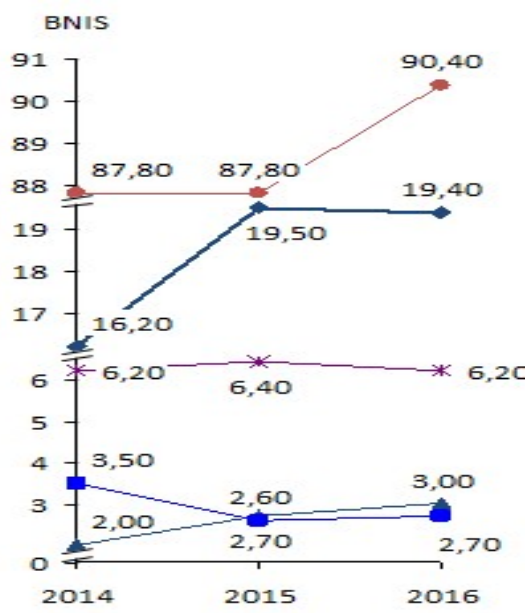

keterangan

Gambar 10 Grafik Gabungan rasio RBBR Bank BNI Syariah (BNIS)

Sumber: Data diolah peneliti 2018 
Dari gambar grafik diatas dapat diketahui bahwa di tahun 2015 terjadi lonjakan kinerja Capital Adequency Ratio CAR (dari 16,2\% ke 19,5\% sangat sehat), sedangkan posisi Loan To Deposit Ratio LDR (cukup sehat) dan Net Interest Margin NIM (sangat sehat) cenderung masih stabil. Hal ini dimanfaatkan BNIS untuk ekspansi kredit pada tahun 2016 sehingga LDR melonjak menjadi 90,4\% (masih predikat cukup sehat) dalam rangka mempertahankan kinerja Return On Asset (ROA) diposisi 2,7\% (sangat sehat). Namun perlu menjadi perhatian bahwa selama 3 tahun terakhir terus terjadi kenaikan kredit bermasalah Non Performing Loan (NPL naik dari 2\% ke 3\% namun masih posisi sehat).

Tabel 7 Predikat Kinerja Bank Syariah Devisa Tahun 2016

\begin{tabular}{clllll} 
& \multicolumn{2}{l}{ Risk Profile } & Earnings & Capital \\
\hline $\mathbf{2 0 1 6}$ & NPL & LDR & ROA & NIM & CAR \\
\hline BMUI & Sehat & Cukup Sehat & Kurang Sehat & Sangat Sehat & Sangat Sehat \\
\hline BSM & Sehat & Sehat & Sangat Sehat & Sangat Sehat & Sangat Sehat \\
\hline MSIB & Sehat & Cukup Sehat & Sangat Sehat & Sangat Sehat & Sangat Sehat \\
\hline PDSB & Sehat & Cukup Sehat & Kurang Sehat & Sehat & Sangat Sehat \\
\hline BNIS & Sehat & Cukup Sehat & Sangat Sehat & Sangat Sehat & Sangat Sehat \\
& & & & & \\
\hline
\end{tabular}

Sumber: Data diolah peneliti 2018

\section{Kesimpulan}

1. Perbankan Syariah Devisa selama periode tahun 2014-2016 cenderung menunjukkan perbaikan kinerja keuangan, dengan predikat kinerja sehat dan sangat sehat pada tahun 2016. Hal ini menunjukkan bahwa seluruh Perbankan Syariah Devisa yang ada telah memenuhi standar minimum peraturan Bank Indonesia.

2. Berdasarkan analisa dari aspek capital, seluruh sampel Perbankan Syariah Devisa menunjukkan hasil kinerja CAR dengan predikat sangat sehat. Bank Mega Syariah Indonesia (MSIB) selama tiga tahun terakhir terus memperlihatkan kenaikan yang signifikan dari 19,26\% menjadi $23,53 \%$.

3. Berdasarkan analisa dari aspek risk profile, Perbankan Syariah Devisa yang dievaluasi menunjukkan hasil kinerja predikat sehat (NPL) dan cukup sehat (LDR).

a. Kendati tahun 2015 kinerja Non Performing Loan (NPL) sempat mengalami penurunan, namun pada tahun 2016 seluruh Perbankan Syariah Devisa mampu melakukan perbaikan kinerja NPL menjadi dibawah $5 \%$ (predikat kinerja sehat).

b. Tahun 2014-2016 sebanyak 4 dari 5 Perbankan Syariah Devisa menunjukkan kinerja Loan To Deposit Ratio (LDR) dengan predikat cukup sehat (LDR diantara 85\% dan 100\%). Adapun Bank Syariah Mandiri (BSM) memiliki memiliki kinerja Loan To Deposit Ratio (LDR) yang paling sehat (LDR $<85 \%$ ) dengan trend yang terus membaik.

4. Berdasarkan analisa dari aspek earnings, rata-rata Perbankan Syariah Devisa menunjukkan hasil kinerja sangat sehat (NIM dan ROA), kecuali pada bank BMUI dan PDSB dengan kinerja ROA kurang sehat.

a. Kinerja Net Interest Margin (NIM) seluruh sampel Perbankan Syariah Devisa tahun 2014-2016 cenderung sangat sehat (NIM $>3 \%)$. Sehingga dapat dikatakan bahwa perusahaan mampu memperoleh keuntungan dari pendapatan bunga.

b. Selama tahun 2014-2016 kinerja Return on Asset (ROA) sampel Perbankan Syariah Devisa cenderung mengalami peningkatan, jika dalam 2 tahun sebelumnya (2014 dan 2015) hanya 2 dari 5 bank sampel yang memiliki ROA diatas 1,25\% maka pada tahun 2016 ada 3 dari 5 bank sampel yang mampu meraih kinerja ROA bahkan diatas 1,5\% (predikat sangat sehat). Adapun Bank BNI Syariah menunjukkan kinerja ROA yang paling baik dengan predikat sangat sehat selama periode tahun 2014-2016. 


\section{Saran}

1. Perbankan Syariah Devisa membutuhkan kecukupan modal (CAR) yang baik dengan dukungan tingkat pendapatan (NIM) yang kompetitif untuk dapat melakukan ekspansi kredit (LDR) dalam rangka untuk menghasilkan value (ROA) bagi stakeholder. Namun perlu diperhatikan risiko kenaikan kredit bermasalah (NPL) serta menjaga suku bunga (NIM) tetap kompetitif untuk mempertahankan kecukupan modal (CAR).

2. Apabila pemilik modal hendak menyimpan dananya di Perbankan Syariah Devisa, berdasarkan hasil penelitian ini disarankan ke bank dengan predikat sehat sebagai berikut: Bank Syariah Mandiri (BSM), Bank Mega Syariah Indonesia (MSIB), dan Bank BNI Syariah (BNIS)

3. Setiap bank yang mengalami penurunan perkembangan nilai rasio NPL, LDR, ROA, NIM dan CAR dari tahun ke tahun diharapkan mampu meningkatkan nilai rasio-rasio yang dimiliki agar dalam kondisi yang sehat sehingga kegiatan operasional bank dapat berjalan dengan baik.

4. Penilaian faktor profil risiko dengan menggunakan rasio LDR menunjukkan bahwa terdapat beberapa bank yang memperoleh predikat cukup sehat. Sehingga nilai rasio LDR perlu ditingkatkan sesuai standar Bank Indonesia dan bank harus selektif dalam memberikan kredit kepada masyarakat agar tidak terjadi kredit yang bermasalah.

\section{DAFTAR PUSTAKA}

Ali, Mashud, 2004. Asset Liability Management, “Menyiasati Risiko Pasar dan Risiko Operasional”, Jakarta. PT. Gramedia.

Andini, Fathitah dan Irni Yusnita.2015.Analisis Pengaruh Return On Asset (ROA), Return On Equity (ROE), Non Performing Loan (NPL), Dan Loan To Deposit Ratio (LDR) Terhadap Capital Adequacy Ratio (CAR) Pada Perusahaan Perbankan Di Indonesia (Studi Kasus Pada Bank Umum Indonesia Yang Terdaftar Di Bursa Efek Indonesia Periode 2009-2013).e-proceeding of management vol 2Agustus 2015. ISBN: 23559357. Universitas Telkom

Bank Indonesia. (2004). Peraturan Bank Indonesia Nomor 6/ 10/ PBI/ 2004 tentang sistem Penilaian Tingkat Kesehatan Bank Umum.

Bank Indonesia. (2004). Surat Edaran Bank Indonesia Nomor. 6/ 23/ DPNP/2004 Tanggal 31 Mei 2004 tentang Sistem Penilaian Tingkat Kesehatan Bank Umum.

Bank Indonesia. 2011. Peraturan Bank Indonesia Nomor: 13/1/PBI/2011 5 Januari 2011 tentang Penilaian Tingkat Kesehatan Bank Umum.

Baridwan, Zaki, 1992. Intermediate Accounting, Edisi Ketujuh, Yogyakarta: BPFE.

Dendawijaya, Lukman. 2003. Manajemen Perbankan. Edisi Kedua. Jakarta: Ghalia Indonesia.

Ikatan Akuntan Indonesia. 2009. Standar Akuntansi Keuangan. Jakarta: Salemba Empat

Irmayanto, Juli dkk. 2009. Bank \& Lembaga Keuangan. Jakarta: Universitas Trisakti.

Jumingan. 2011. Analisis Laporan Keuangan. Jakarta: PT. Bumi Aksara.

Kasmir. 2012. Analisis Laporan Keuangan. Jakarta: PT. Raja Grafindo Persada

Sundjaja, Ridwan dan Inge Barlian. 2001. Manajemen Keuangan Satu. Edisi Keempat. Jakarta: PT Prenhallindo.

Simorangkir. 2004. Pengantar Lembaga Keuangan Bank dan Non Bank. Jakarta: Ghalia Indonesia.

Taswan. 2006. Manajemen Perbankan. Yogyakarta: UPP STIM YKPN.

Taswan. 2010. Manajemen Perbankan Konsep, Teknik dan Aplikasi. Yogyakarta: UPP STIM YKPN

Zainuddin dan Jogiyanto Hartono. 1999. Manfaat Rasio Keuangan Dalam Memprediksi Pertumbuhan Laba, Suatu Studi Empiris pada Perusahaan Perbankan yang terdaftar di Bursa Efek Jakarta. Jurnal Riset Akuntansi Indonesia. Vol. 2. No.1 Januari 1999.

Yacheva,Nora, Muhammad Faifi dan Zahroh Z.A. 2016. Analisis Tingkat Kesehatan Bank Dengan Metode Rbbr (Riskbased Bank Rating) (Studi Pada Bank Umum Swasta Nasional Devisa Yang Terdaftar Di Bursa Efek Indonesia Periode 2012-2014). Jurnal Administrasi Bisnis(JAB) no.1 agustus 2016.Universitas Brawijaya Malang.

\section{Sumber internet:}

https://www.bi.go.id/id/peraturan/perbankan/Pages/pbi\%2062404.aspx, diakses tanggal 20 April 2018 